\title{
Crisis Management during Covid-19 Pandemic
}

\author{
Twinkle* and Kavita Dua \\ Department of Family Resource Management, CCS Haryana Agricultural University, \\ Hisar, Haryana, India \\ *Corresponding author
}

\section{A B S T R A C T}

\begin{tabular}{|l|}
\hline Key w or d s \\
Covid-19 \\
Pandemic, \\
Crisis \\
Management \\
\hline Article Info \\
\hline $\begin{array}{l}\text { Accepted: } \\
\text { 08 December } 2020 \\
\text { Available Online: } \\
\text { 10 January 2021 }\end{array}$ \\
\hline
\end{tabular}

A crisis is defined as a significant threat to operations that can have negative consequences if it's not handled properly. Agha (2020) reported that the primary reason being, that all students are unable to afford online platforms usage and smoothly transition to online learning which can have a huge negative effect on students' career path. Crisis Management is the process (planning, direction and supervision) by which an organization prevents, avoids and management processes that are critical for survival. Crisis Management involves clear roles, responsibilities, requirements in the following areas: crisis prevention, crisis assessment, crisis handling and crisis termination. In times of an pandemic, people tend to experience fear of getting infected with the virus/disease resulting in anxiety, stress, and depression, etc. Stress can be explained as a feeling of emotional and physical tension which arises from any event that threatens our homeostasis. On the other hand, the fear of the unknown is termed as anxiety, that is the body's natural response to stress. Depression is viewed as a state of disinterest in daily activities. It is surmised that people facing a pandemic with no vaccination would result in fear of the unknown (in this case, the corona virus) making them anxious, stressed and depressed.

\section{Introduction}

A crisis is defined as a significant threat to operations that can have negative consequences if it's not handled properly. Crisis Management is the process (planning, direction and supervision) by which an organization prevents, avoids and management processes that are critical for survival. Crisis Management involves clear roles, responsibilities, requirements in the following areas: crisis prevention, crisis assessment, crisis handling and crisis termination. COVID-19 affects different people in different ways. Most infected people will develop mild to moderate illness and recover without hospitalization.

Most common symptoms: fever, dry cough, tiredness, less common symptoms, aches and pains, sore throat, diarrhea, headache, loss of taste or smell, a rash on skin, or discoloration of fingers or toes. To prevent the spread: Clean your hands often. Use soap and water, or an alcohol-based hand rub. Maintain a safe distance from anyone who is coughing or 
sneezing. Wear a mask when physical distancing is not possible. Don't touch your eyes, nose or mouth. Cover your nose and mouth with your bent elbow or a tissue when you cough or sneeze. Stay home if you feel unwell. If you have a fever, cough and difficulty breathing, seek medical attention.

Health care system are severely impacted. Firstly, there are facts about stress, the brain and mental health that can help. There is virtually no disease, illness or injury that is not aided by good mental health. Why? 1.

Our brains and our immune system are deeply linked to each other. The immune system is the prime mediator of environmental agents such as microbes, chemicals and the famous COVID-19. 2. Stress is normal and can be healthy but too much sustained stress is not. High and unregulated levels of stress have a number of negative consequences on the brain, immunity and the vascular system, leading to blood sugar imbalances, high blood pressure and impaired immunity and inflammatory responses - the very precise opposite of what we need to fight the potential impact from COVID-19 exposure. 3.

Physical exercise is an essential component of improving both physical and mental health and regular exercise has been linked to changes in brain connectivity, and increases in brain growth factors (e.g. brain-derived neurotrophic factor) and decreases in oxidative stress which damages cells and tissue. 4.

Mindfulness and relaxation techniques can improve mood and sleep quality through enhancing control over the body's arousal system and focus as well as managing anxiety and concerns. 5. Investing in mental health pays long-lasting dividends. Studies have shown that future mental and physical health is related to previous investments in mental and physical health. The earlier the better but it's never too late. How to recognize early warning signs of an emotional disorder? Unusual decrease in energy and activity level or listlessness, unusual restlessness and excessive worrying, having trouble relaxing or sleeping, severe anxiety or panic attacks, change in eating patterns, easily startled and feeling as-if "on the edge" daily for most of the day, constant complaining or blaming others without any reason with increased irritability and anger outbursts; crying frequently; recurrent unexplained headaches and other bodily pains, increased use of alcohol, nicotine or other drugs; excessive introversion or rebellious behaviors in children, some signs of anxiety in children may include bedwetting, thumb sucking, worsening of tics and hyperactivity

\section{Materials and Methods}

The study was conducted in the month of September, 2020 in Rohtak, Haryana. A total of 30 participants were selected randomly. A questionnaire was created and circulated on and some of the data was asked telephonically.

The data was analyses with the help of SPSS v 21. t-test, Anova and Correlation analysis were carried out to make inferences.

Depression Anxiety Stress Scale (Lovibond and Lovibond, 1995). The 21-item DASS version was used to assess depression, anxiety, and stress. The responses were collected on a 4-point rating scale ranging from:

- 0 "didn't apply to me at all"

- 1 "applied to me some degree"

- 2 "applied to me considerable degree"

- 3 "applied to me very much or most of the time". 
The severity ratings used to interpret are shown below:

\begin{tabular}{|l|l|l|l|}
\hline Seves severity & Anxiety & Depression & Stress \\
\hline Normal & $0-7$ & $0-9$ & $0-14$ \\
\hline Mild & $8-9$ & $10-13$ & $15-18$ \\
\hline Moderate & $10-14$ & $14-20$ & $19-25$ \\
\hline Severe & $15-19$ & $21-27$ & $26-33$ \\
\hline Extremely severe & $20+$ & $28+$ & $34+$ \\
\hline
\end{tabular}

\section{Results and Discussion}

Table- 1 shows the mean differences between males and females. The mean values of anxiety, depression and stress for males were found to be $9.91,10.81,12.65$ respectively, with $8.78,9.99,9.26$ standard deviation. For females, the mean values for anxiety, depression and stress were found to be 10.57 , $10.96,13.44$ with $8.77,9.76,9.72$ as their respective standard deviation. The mean values of females were found to be higher than males. However, no significant difference was observed. Males and females did not differ significantly on anxiety $(\mathrm{t}=0.69, \quad \mathrm{p}=0.50), \quad$ depression $\quad(\mathrm{t}=0.12$, $\mathrm{p}=0.90)$ and stress $(\mathrm{t}=0.73, \mathrm{p}=0.46)$. Both males and females reported mild stress, moderate anxiety, and mild depression.

Table-2 shows group differences on stress, anxiety and depression. On stress, the mean values were found to be $15.57,11.06,14.61$ for students, teachers, health professionals respectively. Their respective standard deviations were found to be $10.39,8.42,7.85$.
A significant difference was observed $(\mathrm{t}=5.06, \mathrm{p}<0.01)$ among different kinds of professionals on stress. Students, teachers and health professionals reported mild stress. On anxiety, the mean values for students, teachers, health professionals were found to be $12.63,8.66,12.55$ with 9.46, 7.30, 6.23 standard deviations respectively. A significant group difference was found on the anxiety scores $(\mathrm{t}=6.28, \mathrm{p}<0.01)$ among different professional groups. Students and health professionals reported moderate levels of anxiety whereas, teachers reported mild levels. As far as the mean values on depression are concerned, students, teachers, health professionals reported 13.97, 7.84, 10.79 with $10.84,7.18,6.56$ standard deviations respectively. A significant difference was also observed among the groups on depression $(\mathrm{t}=5.88, \mathrm{p}<0.01)$. It was evident that teachers reported normal levels of depressions, while health professionals reported mild levels. Moreover, students reported a moderate level of depression.

Table.1 Gender Differences

\begin{tabular}{|l|l|l|l|l|l|l|l|}
\hline VARIABLE & SEX & N & MEAN & SD & LEVEL & t & SIGN \\
\hline ANXIETY & MALE & 15 & 9.91 & 8.78 & MILD & 0.69 & 0.50 \\
\hline & FEMALE & 15 & 10.57 & 8.77 & MILD & & \\
\hline DEPRESSION & MALE & 15 & 10.81 & 9.99 & MILD & 0.12 & 0.90 \\
\hline & FEMALE & 15 & 10.96 & 9.76 & MILD & & \\
\hline STRESS & MALE & 15 & 12.65 & 9.26 & MODERATE & 0.73 & 0.46 \\
\hline & FEMALE & 15 & 13.44 & 9.72 & MODERATE & & \\
\hline
\end{tabular}


Table.2 Difference between different professionals

\begin{tabular}{|l|l|l|l|l|l|l|l|}
\hline VARIABLES & GROUPS & N & MEAN & SD & LEVEL & t & SIGN \\
\hline ANXIETY & STUDENT & 14 & 12.63 & 9.46 & MODERATE & 6.28 & $<0.01$ \\
\hline & TEACHING & 12 & 8.66 & 7.30 & MILD & & \\
\hline & $\begin{array}{l}\text { HEALTH } \\
\text { PROFESSIONALS }\end{array}$ & 04 & 12.55 & 6.23 & MODERATE & & \\
\hline DEPRESSION & STUDENT & 14 & 13.97 & 10.84 & MODERATE & 5.88 & $<0.01$ \\
\hline & TEACHING & 12 & 7.54 & 7.18 & NORMAL & & \\
\hline & $\begin{array}{l}\text { HEALTH } \\
\text { PROFESSIONALS }\end{array}$ & 04 & 10.79 & 6.56 & MILD & & \\
\hline STRESS & STUDENT & 14 & 15.57 & 10.39 & MILD & 5.06 & $<0.01$ \\
\hline & TEACHING & 12 & 11.06 & 8.42 & MILD & & \\
\hline & HEALTH & 04 & 14.51 & 7.85 & MILD & & \\
& PROFESSIONALS & & & & & & \\
\hline
\end{tabular}

Table.3 Correlation co efficient

\begin{tabular}{|l|c|c|c|c|}
\hline VARIABLE & ANXIETY & DEPRESSION & STRESS & $\begin{array}{c}\text { FAMILY } \\
\text { INFLUENCE }\end{array}$ \\
\hline ANXIETY & & $0.70^{* *}$ & & $-0.18^{* *}$ \\
\hline DEPRESSION & & & & $-0.19^{* *}$ \\
\hline STRESS & $0.73^{* *}$ & $0.81^{* *}$ & $-0.20^{* *}$ \\
\hline
\end{tabular}

Table.3 indicate the correlation between stress, anxiety, depression, and family affluence. All the correlation coefficients were found to be significant. All three aspects of psychological distress (stress, anxiety and depression) shared a high significant positive correlation with each other. The correlation coefficients between stress and anxiety and stress and depression were found to be 0.73 and 0.81 . However, between anxiety and depression, the correlation coefficient was found to be 0.70 . As far as family affluence was concerned, it shared a relatively small but significant negative correlation with stress $(\mathrm{r}=-0.20), \quad$ anxiety $\quad(\mathrm{r}=-0.18), \quad$ and depression $(\mathrm{r}=-0.19)$.

The main aim of the research was to explore the levels of psychological distress (anxiety, depression and stress) among different sections of people. The data was collected from different professionals including students for this study. As far as gender differences on anxiety, depression and stress were concerned, both males and females seemed to suffer equally. The levels of stress and depression were found to be mild, whereas the levels of anxiety were moderate among males and females. This could be because the current un lockdown and fear of getting infected with Covid-19 are so pervasive, that similar experiences of distress are evident irrespective of gender. Even though levels of stress and depression were found to be moderate, severe anxiety issues which could be attributed to the current situation were evident.

In conclusion, the present study is a frontrunner in exploring levels of anxiety, 
stress, and depression in the Indian population. The research findings indicate that students, teachers and health professionals need special attention because of their higher psychological distress. It is imperative that governments, NGOs and other agencies that are instrumental in distributing and delivering (daily essentials) focus more on people who do not have enough supplies. Lastly, policymakers also need to care for students and health professionals as the main stakeholders in the society.

Be kind to you mind. pause. Breathe. Notice how you feel. Take break from Covid-19 contents. Make time to sleep and exercise. Reach out and stay connected. Seek help if overwhelmed or unsafe.

\section{References}

Agha, E. (2020, April 14). Learning rebooted: Online education during Covid-19 lockdown puts spotlight on India's digital divide.

Bansal, V. (2020, April 17). Online therapy platforms offering anonymity are helping India's Covid-19 related mental health crisis. Retrieved from https://entrackr.com/2020/03/onlinetherapy-covid-19-mental-healthcrisis/.

Cao W, Fang Z, Hou G, Han M, Xu X, Dong J, Zheng J. The psychological impact of the COVID-19 epidemic on college students in China. Psychiatry Research. 2020 doi: 10.1016/j.psychres.2020.112934.

Chetterje P. Gaps in India's preparedness for COVID-19 control. The Lancet Infectious Diseases. 2020;20(5):544. doi: 10.1016/s1473-3099(20)30300-5.

Cheng V, Wong S, Chuang V, So S, Chen J, Sridhar S, et al., The role of community-wide wearing of face mask for control of coronavirus disease 2019 (COVID-19) epidemic due to SARS-CoV-2. Journal of Infection. 2020 doi: 10.1016/j.jinf.2020.04.024.

Currie C, Molcho M, Boyce W, Holstein B, Torsheim T, Richter M. Researching health inequalities in adolescents: The development of the Health Behaviour in School-Aged Children (HBSC) Family Affluence Scale. Social Science \& Medicine. 2008;66(6):1429-1436. doi: 10.1016/j.socscimed.2007.11.024.

Roy D, Tripathy S, Kar S, Sharma N, Verma S, Kaushal V. Study of knowledge, attitude, anxiety \& perceived mental healthcare need in Indian population during COVID-19 pandemic. Asian Journal of Psychiatry. 2020; 51:102083. doi: 10.1016/j.ajp.2020.102083.

Sahu D, Agrawal T, Rathod V, Bagaria V. Impact of COVID 19 lockdown on orthopaedic surgeons in India: A survey. Journal of Clinical Orthopaedics and Trauma. 2020 doi: 10.1016/j.jcot.2020.05.007.

Sahu P. Closure of universities due to Coronavirus Disease 2019 (COVID19): Impact on education and mental health of students and academic staff. Cureus. 2020 doi: 10.7759/cureus.7541.

Sanders J, Monogue M, Jodlowski T, Cutrell J. Pharmacologic treatments for Coronavirus Disease 2019 (COVID19) JAMA. 2020 doi: 10.1001/jama.2020.6019. [PubMed] [CrossRef] [Google Scholar]

Selye H. The stress of life. New York: McGraw-Hill; 1956. [Google Scholar]

Usher K, Durkin J, Bhullar N. The COVID19 pandemic and mental health impacts. International Journal of Mental Health Nursing. 2020 doi: 10.1111/inm.12726. 
Van Bortel T, Basnayake A, Wurie F, Jambai M, Koroma A, Muana A, et al., Psychosocial effects of an Ebola outbreak at individual, community and international levels. Bulletin of the World Health Organization. 2016; 94(3):210-214.

doi: 10.2471/blt.15.158543.

Wang C, Pan R, Wan X, Tan Y, Xu L, Ho C, Ho R. Immediate psychological responses and associated factors during the initial stage of the 2019 Coronavirus Disease (COVID-19) epidemic among the general population in China. International Journal of Environmental Research and Public Health. 2020;17(5):1729. doi: 10.3390/ijerph17051729. [PMC free article] [PubMed] [CrossRef] [Google Scholar]
WHO. (2020). Mental health and psychosocial considerations during the COVID-19 outbreak [Ebook]. Retrieved from https://www.who.int/docs/defaultsource/coronaviruse/mental-healthconsiderations.pdf.

Worldometers. (2020, April 13). Retrieved from https://www.worldometers.info/corona virus/.

Xiang Y, Yang Y, Li W, Zhang L, Zhang Q, Cheung $\mathrm{T}, \mathrm{Ng}$ C. Timely mental health care for the 2019 novel coronavirus outbreak is urgently needed. The Lancet Psychiatry. 2020;7(3):228-229. doi: 10.1016/s2215-0366(20)30046-8.

\section{How to cite this article:}

Twinkle and Kavita Dua. 2021. Crisis Management during Covid-19 Pandemic. Int.J.Curr.Microbiol.App.Sci. 10(01): 675-680. doi: https://doi.org/10.20546/ijcmas.2021.1001.081 